\title{
Afetos. Estudos Queer e Artifício na América Latina ${ }^{1}$
}

Denilson Lopes

\section{Resumo}

Busco um diálogo entre a discussão sobre afetos como proposta por Deleuze e Guattari e os estudos queer. Deleuze e Guattari, claramente, defendem uma compreensão da obra de arte como blocos de sensações, formados por afetos e perceptos. Por sua vez, em obras recentes nos estudos queer em língua inglesa, o termo afeto aparece sem uma clara definição, mas como uma estratégia para ir além de uma política de identidades e diferenças. A proposta é que podemos encontrar uma resposta na genealogia de uma produção latino-americana centrada no artifício, dando especial ênfase ao camp. Como forma de comprovar a rentabilidade da aproximação entre estudos queer e artifício à estética da comunicação e os estudos da arte, faremos uma breve análise do filme Canto de Outono (2014), de André Antônio, a partir de uma segunda forma do artifício: 0 dândismo.

\section{Palavras-Chave}

Afeto. Artifício. Camp. Dândismo. Estudos queer.

Denilson Lopes I noslined@bighost.com.br Professor associado, coordenador do Programa de Pós-Graduação em Comunicação e Cultura da UFRJ e pesquisador do CNPq.
Qual é a relação entre a compreensão da obra de arte por Deleuze e Guattari (1992) como blocos de sensações formados por afetos e perceptos, ao invés de noções como forma, conteúdo ou representação, e os estudos queer²? Alguns autores associados aos estudos queer, tais como José Muñoz (2009), Jack Halbertam (2011) e Jennifer Doyle (2013) que escreveram, respectivamente, sobre utopia, fracasso e dificuldade, poderiam sugerir pistas para este caminho. Contudo, eles não realizam, ao menos explicitamente, um questionamento teórico e conceitual sobre afetos, discutindo afetos ou emoções particulares. A conhecida leitura de Eve Sedgwick e Adam Frank sobre Silvan Tomkims (2003) a respeito da vergonha não me trouxe sugestões ricas no campo da estética ou da arte, embora a sua crítica cada vez mais ensaística abra possibilidades para discutir 0 afeto e a experiência da crítica no ato da escritura e da pesquisa. Mesmo o trabalho de Lauren Berlant, ainda não consegui dialogar neste caminho. De minha parte, ainda ando à procura do que "queer affect" possa dizer ou revelar. Apesar dos esforços de Lauren Berlant, bem pouco achei na 
bibliografia latino-americana, na constituição do que seria "queer affect". Apesar do verdadeiro boom nas universidades em língua inglesa em trabalhos sobre 0 afeto, denominado mesmo como uma virada afetiva ${ }^{3}$, esta questão parece ainda pouco explorada na América Latina. Não pretendo mapear como os estudos sobre afeto podem ser cartografados no contexto latino-americano, mas gostaria de avançar uma ideia que é uma proposta de estudo de que este afeto queer pode ser procurado à sombra do artifício, notadamente no camp. Depois, a partir do artifício e do camp, gostaria de sugerir uma leitura outra de filmes brasileiros contemporâneos, já sugerindo uma terceira estética do artifício, a qual também se atualiza no contemporâneo centrada no dândismo.

Foi um acaso que me fez procurar esta busca de um olhar crítico também a partir de uma genealogia queer na América Latina, tendo como ponto de partida o Brasil (e é importante frisar isso). No campo teórico dos estudos de gênero, tenho a impressão de que estamos muito reféns da lógica do comentário, da introdução ou da defesa, mas raramente da apropriação, sobretudo do que vem ou passa pela academia norte-americana. Nesse sentido, a importância de trabalhos como os de Carlos Monsivais, Néstor Perlongher, Sylvia Molloy, Silviano Santiago, Pedro Lemebel, Suely Rolnik, Gloria Anzaldua, para mencionar apenas alguns, é crucial para irmos além de uma submissão epistemológica nos estudos queer. A busca de uma real discussão, da polêmica que aprofunda a compreensão, a busca de diálogos alternativos parecem que deve ainda caminhar muito para ampliar as sugestões do que já foi feito e de não sufocar outras genealogias. Trata-se também de ampliação de repertório onde até as leituras de Judith Butler - a autora queer mais canônica e já alçada como referência na filosofia e nas humanidades, para além dos estudos de gênero - são restritas a seus primeiros livros, Gender Troubles (1990) e Bodies that Matter (1993), quase em uma homilia sobre performatividade do gênero a ser repetida, pouco questionada, problematizada, deglutida, descartada, ampliada.

Para este desafio, a obra de Silviano Santiago me ajudou e me ajuda. Como Sylvia Molloy, sobre quem abordarei mais à frente, sua experiência de

Versões anteriores e resumidas deste ensaio foram apresentados como palestras nos Seminários "Forms of the Affect (New York University, 2015), "Por Uma Estética do Século XXI" (Museu de Arte do Rio de Janeiro, 2015), "Cultura y Afectividad" (Universidade Autônoma do México, 2015) e na Universidade Três de Fevereiro (Buenos Aires, Argentina, 2015).

Aqui considerada a área de estudos que se cristaliza, nos anos 90 do século passado, não só nos países de língua inglesa, mas também em países como Brasil, enformada, sobretudo, pelos estudos feministas, pelos movimentos e estudos LGBT e pelo pensamento francês da diferença, transitando da questão da orientação sexual, da diferença sexual para a discussão da norma, em especial, hetero e homonormatividades, articulando questões de gênero, raça/etnia, classe social, experiência metropolitana/pós-colonial, entre outros. 
estudo e trabalho, como professor e escritor, é marcada por um estar entre Brasil e 0 exterior (França, EUA, América hispânica), que aponta tanto na sua ficção como nos ensaios uma reelaboração do autobiográfico que passa pela intersecção entre gênero e a condição estrangeira, em mais uma zona de contato (PRATT, 1999), um entre-lugar, para usar a própria expressão cunhada por Santiago (1978), em mais uma experiência intervalar que constitui seu trabalho. Como falar de particularidade sem incorrer em isolacionismo nem ao mesmo tempo negar diálogos? Como fazer diálogos que não sejam o primado da cópia e da subserviência? Creio que 0 entre-lugar, expressão que Santiago começa a formular no fim dos anos 1960, abriu um caminho fecundo em diálogo com a antropofagia cultural, a traição da memória e a noção de corte radical (SANTIAGO, 1982, pp. 19-20), que se traduziu, nos últimos escritos dele, em repensar o cosmopolitismo, e não mais a formação da nação, mas a busca de inserção do Brasil no mundo, como já havia feito em relação à América Latina. Nesse sentido, as questões de gênero, para além das discussões sobre exílio, diáspora e migração, se dão no quadro instável de paisagens transculturais, sobretudo midiáticas para usar a conhecida expressão de Appadurai (1996) de mediascapes, em que cada vez importa menos de onde se veio e mais para onde se vai e os encontros inesperados que acontecem.
Por fim, para pensarmos aquém, através e além do queer e afeto na cultura e arte, apostamos em outro termo de difícil tradução: 0 camp. 0 camp nos interessa à medida que ele se insere no artifício. É importante lembrar, como apresentamos em nosso artigo Terceiro Manifesto Camp (LOPES, 2002), que: "0 artifício é uma categoria conceitual, sóciohistórica, estética, articuladora de diferentes produtos culturais e mediadora entre estes e a vida material, que deve ser pensada não tanto como uma simples oposição à realidade, mas como um dissolvente da dualidade real versus irreal. Ao contrário de categorias abstratas, transcendentais, definidas $a$ priori, o artifício é uma categoria material, constituída pelas experiências individuais e coletivas, que será colocada, no momento, com especial ênfase no horizonte das experiências queer contemporâneas" que nos interessa aqui. Sintetizando, o que já disse de forma dispersa, 0 artifício possui um vasto campo semântico, da teatralidade barroca à simulação midiática, da tradição do travestimento nas artes cênicas aos desafios da performatividade do sujeito contemporâneo. Para estabelecer a genealogia de uma estética do artifício contemporânea, antinaturalista e antiautêntica, seria necessário revisitar não só o Barroco, a partir da metáfora do teatro do mundo (LOPES, 1999, pp.92/4) e estilos próximos, como o Maneirismo, o Rococó, o Preciosismo e, por extensão, o Neobarroco, como também o esteticismo decadentista (MUCCI, 
1994), 0 art nouveau e o dândismo ${ }^{4}$ na música pop, e, naturalmente, o camp, sem esquecer da tradição libertina do século XVIII.

No contexto norte-americano, foi o conhecido "Notes on Camp", de Susan Sontag, publicado como artigo em 1964 e, em Against Interpretation (1966), que deu ao camp status intelectual para um público mais amplo, posteriormente sofrendo uma série de críticas de desdobramento no campo dos estudos LBTQ. A partir deste trajeto, entendo o camp não só como prática social, mas, sobretudo, seguindo Sontag, como sensibilidade, ou, como preferimos, como categoria estética. "0 camp se caracteriza por uma predileção pelo artificial e pelo exagero, por um tipo de esteticismo, uma forma de ver o mundo como um fenômeno estético" (SONTAG, 1987, 318/20). Naturalmente, é bom lembrar que o camp tem profundas raízes na cultura do melodrama e no fascínio pelas divas do cinema, da música popular, e, depois, das novelas, no contexto latino-americano. 0 camp estabeleceu diálogo entre as mais diversas artes, quebrou fronteiras entre cultura erudita, popular e massiva, em um contexto maior proposto por Néstor Garcia Canclini (1987).

Na busca de pensar o camp não como estratégia e comportamento datados, associados ao clichê da bicha louca, ao homossexual masculino afetado, anterior ao gay moderno, urbano e desejoso de se integrar em padrões hetero e homonormativos, é o que 0 trabalho de Néstor Perlongher, realizado entre Argentina e Brasil, entre poesia e etnografia, entre militância e as ruas, é de fundamental importância, bem como para pensar um olhar queer distinto de uma tradição norte-americana. Antes lembrado ora como poeta pelos críticos literários, ora como antropólogo por Negócio do Michê (1987), tensionando, de forma pioneira, Deleuze e os estudos de gênero, seus escritos têm sido resgatados tanto na Argentina como no Brasil como precursor dos estudos queer por uma nova geração de pesquisadores (MISKOLCI, PELÚCIO, 2008; PALMEIRO 2011; MAIA 2014). Mas talvez haja outras formas de atualizar sua obra.

Ainda que Prosa Plebeya (1997), talvez seu livro de ensaios fundamental e que reúne esta discussão, tenha sido póstumo, seus ensaios espalhados não deixam de constituir uma importante contribuição para pensar a bicha louca (la loca), não no seu aparente anacronismo diante do pânico da AIDS e da valorização da monogamia hetero ou homonormativa, mas como força disruptiva. Esta sensibilidade protoqueer se articula com uma produção poética vinculada a uma releitura do Barroco, momento fundamental de uma genealogia do artifício e que se atualiza enquanto Neobarroco, o qual já se colocava sob uma dimensão queer enquanto estranho e recusa de uma heteronormatividade, como 
podemos ver em Lezama Lima (QUIROGA, 2000, pp. 1/49) e, explicitamente, nos ensaios de Severo Sarduy, em especial em La Simulación (publicado originalmente em 1982 e incluído em sua coletânea de ensaios Ensayos Generales sobre el Barroco, de 1987). Este Neobarroco, como sabemos, foi traduzido e recriado na Argentina, como Neobarroso, por Perlongher, Lamborghini, entre outros. Esta genealogia, destaca Juan Pablo Sutherland (2009, p. 15), chega a traduzir o queer como barroco ou maneirista (ECHEVERRÍA, 1997), estabelecendo um longo arco marcado pelo artifício que vai do século XVII até o presente.

Esta genealogia do artifício não só se contrapõe aos realismos, à obra de arte como documento, à figura do artista como fotógrafo e cronista de fatos, mas também afirma uma política que transita pelo humor e pelos jogos das aparências, que encontra um outro momento de cristalização na virada do século XIX para o século XX. Em diálogo com 0scar Wilde, o esteticismo e 0 dândismo criaram todo um universo de referências que talvez tenham ficado esquecidas, mas recuperadas pelos textos reunidos por Juan Pablo Sutherland em Cielo Dandi (2011), e que atinge um ponto central nas reflexões de Sylvia Molloy, especialmente em Pose del Fin del Siglo (2012), livro que sintetiza não só sua contribuição aos estudos de gênero, mas seu importante papel como formadora de diversos pesquisadores nessa área de estudos. Este livro não pretende ser uma resposta abstrata aos estudos queer, porém o que acontece, como nos lembra Silviano
Santiago (2004, p. 197), quando nos defrontamos com um "material inédito". É uma resposta não só genealógica ao que estou chamando de uma estética do artifício, mas também uma resposta já explicitada em seu artigo La cuestión del género: propuestas olvidadas y desafíos críticos (MOLLOY, 2000, p. 816) a uma postura dos intelectuais latino-americanos diante das questões de gênero, a qual já se traduzia no silenciamento que Sarmiento tem em 1845, quando, viajando, encontra quatro homens morando juntos em uma ilha (idem, p. 816). Silenciamento que persistirá por muito tempo, como vemos no gesto do cineasta João Moreira Salles em Santiago (2007), filme sobre o mordomo argentino da rica família Moreira Salles à qual o cineasta pertence. No fim do filme, quando o diretor desliga a câmera, mas não 0 som, é quando, finalmente, o mordomo tenta sair da narrativa do mundo de seu patrão que agora o filma, das festas e pessoas importantes que transitaram pela rica casa da Gávea no Rio de Janeiro, de seu fascínio por nobres do passado e deseja falar de si, ao querer declamar um soneto sobre, nos termos de personagem, "seres malditos" a que ele julgava pertencer. A percepção do silenciamento do patrão-cineasta sobre 0 empregado-ator vem tardia e melancólica na voz autobiográfica do narrador, gravada muito tempo depois do fato acontecido. 0 que resta, além do silenciamento, mais do que contranarrativas aos grandes relatos nacionais (MOLLOY, 2000, pp. 816/7), são gestos e poses que Molloy recolhe com sensibilidade e delicadeza, sem deles tirar grandes sentidos, 
mas longe de mera preocupação museológica, eles apontam para uma intervenção também no presente, como a autora coloca em uma série de sugestões de leituras no fim de seu ensaio que pode ser sintetizado assim: "Lo que yo propondría como ejercicio crítico a partir del género es la intervención (ya que necesariamente no puede ser visible) de una relectura llamativa, en el doble sentido de este término, es decir notable, escandalosa si se quiere, y a la vez eficazmente interpeladora; una relectura no tanto para rescatar textos olvidados o 'mal leídos' como indiqué, sino para fisurar lecturas establecidas" (idem, pp. 818/9). De forma a acentuar esta releitura dessas figuras entre dândis e afetados que fazem de si um espetáculo, destacamos a questão que Molloy (idem, p. 819) faz: “¿cómo analizar desde el género la popularidad de ciertos intelectuales - pienso en un Salvador Novo, un Manuel Mujica Láinez, esos Liberaces de la cultura latino-americana - quienes visibilizan a ultranza una sexualidad disidente a través del trabajo de pose a la vez que son reconocidos, incluso celebrados, como portavoces de un estado conservador cuya doxa propagan?". Salvador Novo: Lo Marginal en el Centro (2000), de Carlos Monsivais, parece vir de encontro à questão levantada por Molloy. Também no Brasil, a resposta ao dândismo passa não só por uma revisitação de João do Rio, sem as conotações políticas conservadores que Molloy indica em Novo e Láinez, chamado de o 0scar Wilde brasileiro, mas que, diferentemente de Wilde, morre no auge do prestígio e da popularidade. Apesar de boa bibliografia, sua releitura do dândismo precisa ser mais explorada (ANTEL0, 1989; GREEN, 2000, pp. 94/106; LEVIN, 1996), mas também da figura de Gonzaga Duque, estudado pelo esforço de Vera Lins (1991, 1996), crítico de arte (1997) e autor de um único romance, pouco conhecido e de inspiração decadentista sobre a vida boêmia do Rio de Janeiro na segunda metade do século XIX, Mocidade Morta, publicado originalmente em 1899, e só resgatado com uma edição revista e disponível, com importante posfácio de Alexandre Eulálio, em 1955, e reeditado em 1995. Uma outra constelação ainda mais ampla no espaço e no tempo remete a um dos mais emblemáticos, 0 conde Robert de Montesquiou, que inspirou 0 protagonista de Às Avessas, de Huysmans (1884), e do Barão de Charlus, de Em Busca do Tempo Perdido, de Marcel Proust, personagem que foi encarnado por Alain Delon em Um Amor de Swan (1983), na adaptação de Volker Schlöndorf e, de forma mais bem-sucedida, na adaptação de Raoul Ruiz, em 0 Tempo Redescoberto (1999), em que 0 personagem foi interpretado por John Malkovitch. 0 livro Proust's Latin Americans, de Rubén Gallo (2014), que estabelece um estimulante diálogo entre história cultural e história literária, entre Proust e sua convivência com latino-americanos, poderia ganhar um desdobramento mais pelas afinidades literárias com o mítico Mario Peixoto, autor de um único filme (Limite, 1931), durante muito tempo dado como perdido e só muito recente com cópia bem próxima do original, e de um projeto de roman fleuve chamado 0 Inútil de Cada Um (1984), do qual só há disponível, ao menos em publicação, seu primeiro volume. 
Os desdobramentos conceituais do artifício podem ser pensados contemporaneamente no camp (e talvez o dândismo) como uma comunidade sentimental transnacional (QUIROGA, 2000, p.151) ou no elogio do estilo em contraponto à moda feito no estimulante Arte Andrógino (1998), de Roberto Echavarren, onde defende que "o estilo não é somente a produção do que aparece - 0 dândi, o roqueiro - mas se relaciona com modos de vida" (ECHAVARREN, 1998, p. 10), sendo que estilo de vida e política estão imbricados (idem, p. 75). Apesar do livro não remeter a muitas situações na América Latina, tem ricas sugestões ao interligar estilo e modo de vida para além das conhecidas discussões culturalistas de subculturas ou de comunidades. Apesar de não explicitar muito contato o debate de gênero como processado pelos estudos LGBTQ ou feministas, aproxima-se mais do desejo do resgate de Foucault de uma estética da existência que associa ética e estética à medida que "o estilo é autoformação ou criação equivalente ao que chamamos uma obra de arte" (idem, p.47), na busca não tanto de uma "identidade gay, lésbica ou queer mas de identificações momentâneas ou duráveis" (idem, p. 35), apontando para a morte do homem, da mulher (idem, p. 50) mas também da homossexualidade (idem, p. 60). 0 andrógino, para Echavarren, é um mutante marcado pelo devir do estilo (idem, p. 60), abre uma outra possibilidade distinta e provocadora ao colocar não só a loca, mas o travesti e 0 transexual "ícones neoclássicos, manifestações de um cânone conservador" (idem, p. 54). Falando a partir de um lugar que pensa 0 gênero como performatividade distinto dos estudos de transgênero ou os transfeminismos, Echavarren propõe um caminho particular ao afirmar que "se 0 estilo vai ao desconhecido, 0 travesti regressa ao óbvio, a supermulher, a uma hipermoda, um estilo secundário que mimetiza e satiriza a moda" (idem, p. 55). 0 Estilo é uma anomalia (idem, 81).

Por outro lado, a loca, criticada anteriormente por Echavarren, retorna no título do mais completo levantamento da teoria queer no Brasil feita por Fernando Benetti (2013), bem como encontra equivalente, no Chile, em Nación Marica (2009), de Juan Pablo Sutherland. Os dois trabalhos mostram que não só há traduções, assim como ampliam ainda mais as possibilidades dos termos em espanhol e em inglês, lembradas por Stoker (2009, p. XI), além de outros caminhos para os estudos de gênero e sexualidade nos estudos latino-americanos. "En Perlongher, la loca conforma un devenir sexual que conjugará su deambular en medio del peligro, de los putos, de la noche como contexto habitual de una política de cuerpos traficado" (SUTHERLAND, 2009, 22). 0 que era corpo estranho para Guacira Lopes Louro (2004) ou algo intraduzível para tantos, ousa dizer o seu nome em português e em espanhol ${ }^{5}$. E o neobarroco, 0 camp e 0 dândismo fazem parte desse vocabulário. 


\section{A volta do artifício no cinema brasileiro}

Como já disse, se há uma histórica hegemonia

do real, estudar talvez 0 artifício em suas várias

encarnações possa ter algo a nos dizer hoje, especialmente, no que estou preocupado aqui, na articulação entre afeto, artifício e um olhar queer. Poderíamos falar como o camp descontrói a opressão e a solidão e cria novos modos de vida desde Madame Satã (2002), de Karim Aïnouz, a Doce Amianto (2013), de Guto Parente e Uirá dos Reis ${ }^{6}$, sobre os quais já escrevi . Mas o que gostaria de me deter são nos trabalhos do coletivo Surto \& Deslumbramento, formado, sobretudo, por estudantes de doutorado ou recém-doutores da Universidade Federal de Pernambuco, especialmente em Canto de Outono ${ }^{7}$ (2014), de André Antônio Barbosa.

Se já, em outro momento (LOPES, 2002), mapeei a bibliografia sobre o camp e seu processo de recusa, crítica e revalorização no contexto dos estudos LGBTQ, a questão do dândismo conheço bem menos, mas a ela voltarei em diálogo com o filme

Canto de Outono, de André Antônio Barbosa ${ }^{8}$, que faz um interessante diálogo entre uma obra artística e seu projeto de doutorado em desenvolvimento, sob minha orientação, chamado "Os labirintos da frivolidade: cinema contemporâneo e artifício", em que, nos seus próprios termos, se propõe a estudar: um fenômeno estético que pode ser observado em vários cineastas e filmes recentes no contexto do cinema global: 0 interesse crescente pelo que chamamos, aqui, de uma estética da frivolidade, em contraposição a uma estética da revelação do real que dominou a década de 1990 e 0 início dos anos 2000. Nossa hipótese é que tal estética do "real" encontra-se numa espécie de esgotamento dentro do capitalismo de controle contemporâneo, onde 0 que antes era considerado - pelo pensamento modernista - uma força subversiva da imagem cinematográfica, hoje possui cada vez mais um lugar confortável e assegurado no campo institucional e mercadológico do "cinema independente".

Nesse contexto, muitos realizadores - brasileiros e de outros países - têm experimentado uma nova atitude perante à imagem, uma atitude que propomos descrever como frivola: mais fria e cética, sem as crenças revolucionárias românticas e as tentativas de transcendência quase religiosa da estética modernista. Uma sensibilidade estetizante e teatralizante, sem um dever auto-imposto de heroísmo moral e social na realidade. Um olhar leve, lúdico, irônico, camp, que se interessa mais em perder-se radicalmente nos labirintos infinitos e coloridos da forma-mercadoria do que encontrar-se na salvação sublime do real. Essa nova sensibilidade, longe de significar que exista qualquer espécie de "crise" na produção fílmica, dá visibilidade a um momento de nossa cultura onde os artifícios, as mercadorias e as imagens desempenham um papel sem precedentes.

Uma crítica informada apenas pelo pensamento modernista poderia considerar os filmes que se constituem a partir dessa sensibilidade como meras celebrações da artificialidade do capitalismo e da leviandade da mercadoria. Porém acreditamos que, em nosso contexto, essa leitura seria redutora. Pretendemos, pelo contrá-

Membros do coletivo de artistas Alumbramento atuante em Fortaleza, no Ceará.

Disponível em https://vimeo.com/100215405

Citação retirada do texto de qualificação de André Antônio Barbosa. 
rio, compreender a sensibilidade nova em jogo nesse cinema como uma resposta ativa ao reinado contemporâneo inédito da mercadoria. É uma forma cinematográfica complexa que, ao jogar com a superfície e contrapor um tom propositalmente "fraco" e libertino às intensidades profundas e sérias da estética modernista (que agora se transformou ela própria em uma mercadoria de nicho), precisa ser compreendida e examinada de maneira mais detida. Ela está em filmes como os de, dentre outros, Uirá dos Reis, Guto Parente, Tavinho Teixeira, Gustavo Vinagre, Leonardo Mouramateus, Salomão Santana, Anita Rocha, Gabriel Martins, Maurílio Martins (Brasil); David Lynch, Todd Haynes, Harmony Korine, Sofia Coppola, Wes Anderson (Estados Unidos); Miguel Gomes, João Pedro Rodrigues (Portugal); François Ozon (França), Xavier Dolan (Canadá); Aki Kaurismäki (Finlândia), Wong Kar-Wai, Hou Hsiao-Hsien (China); Hong Sang-Soo (Coréia do Sul). (BARBOSA, 2014)

Mas voltemos ao filme Canto de Outono, do pesquisador-realizador: a evocação de Baudelaire num poema em tom crepuscular e decadentista, trata-se menos de impotência num mundo em que não se percebe nada a ser mudado ou que nada valha a pena ser mudado. É mais um deslocamento do sentido, um olhar para um outro lado, como nos convidava Roland Barthes em 0 Prazer do Texto, publicado originalmente em 1973. De todo modo, o mundo aqui não é 0 das revoltas, revoluções e manifestações, não é o do Estado nem dos movimentos sociais, não é o das grandes ou pequenas causas públicas. 0 jovem protagonista tem traços físicos de um efebo, mas parece já não mais sê-lo, como os atores de quase 30 anos que fazem papéis de adolescentes em seriados para televisã $0^{9}$. Ele está rodeado por objetos (relógio-despertador, móveis pesados de madeira, candelabro de velas), os quais o colocam meio fora do tempo, anacrônico. Sozinho em casa, a leitura parece preencher seu tempo, como beber ou jogar cartas. 0 outono, mais do que uma estação, é uma paisagem afetiva, já anunciada pelos galhos secos, não fora, mas dentro da casa, usados como decoração. A casa é artificial, sob uma luz rosa, se coloca como cenário, caráter realçado pela claquete no final, nos fazendo lembrar a casa do protagonista de Às Avessas, de Huysmans, clássico do dândismo do século XIX, onde cada aposento continha uma ambiência distinta para que ele não precisasse sair pelo mundo, considerado por ele bem menos interessante do que sua casa. Todavia, não se trata de buscar um distanciamento desprovido de afeto, nem se trata de distanciamento brechtiano e menos ainda de uma projeção, identificação, empatia, de excesso, como no melodrama.

0 mundo do protagonista também é 0 das sensações. Ele é atravessado pelo tédio, este grande temor do homem moderno, como desenvolve Leo Charney em Empty Moments (1998), e caminha pela festa não em busca de momentos de inversão, como no carnaval estudado por Bakhtin, nem de transgressão como em orgias. Apenas caminha entre 
aparições fugazes destinadas ao esquecimento, mais ator de sensações teatralizadas e afetos performatizados na imagem ${ }^{10}$ do que sujeito que expressa emoções e sentimentos. Ele mesmo uma aparição entre outras, como era um objeto entre outros em sua casa. Ele mesmo também destinado ao esquecimento, como a festa que, em breve, acabará. Quando retorna para casa, nem sabemos se aquilo tudo existiu, se não foi um devaneio de leitura, uma fantasia, um sonho. Nada de heroísmo na busca de prazeres inusitados que Konstasntinos Kaváfis buscava nas noites de Alexandria. Sem medo do tédio nem da solidão, o protagonista transita sem se deter num espaço marcado por uma encenação atmosférica, um mood, mais do que por uma narrativa, um enredo, em que os personagens frágeis e fugazes não têm dramas psicológicos a serem aprofundados ou desenvolvidos. 0 diálogo está ausente, como se nós, espectadores, estivéssemos também na festa, mas não suficientemente perto para ouvir o que é falado. De todo modo, o importante é ver a música, sentir os encontros.

A festa que acontece em boa parte do filme se dá em um antigo palacete repleto de pessoas, sobretudo jovens. Trata-se do belo prédio do Parque Lage, cenário de vários filmes como os clássicos Terra em Transe, de Glauber Rocha, e Macunaíma, de Joaquim Pedro de Andrade, mas estas referências cinematográficas e históricas pouco importam. 0 prédio interessa como criação de uma atmosfera irreal e fora do tempo, criada pelo constante trânsito do personagem e de uma música que, incialmente, cria uma expectativa, demonstrada, talvez, também pelos olhos nos celulares. Como se 0 protagonista fosse de encontro a alguém, mas, mesmo depois dos encontros com conhecidos, o ritmo de expectativa se mantém. Nem a festa, nem os encontros com amigas ou uma paquera ocasional parecem ser muito significantes, embora não sejam desimportantes. 0 que importa é a fluidez dos corpos entre espaços iluminados por cores distintas. 0 sexo parece importar pouco, ao contrário da orgia das sensações, vindas das cores e da música. A festa talvez mereça ser melhor estudada como forma de dramaturgia, construção de personagens e não só encenação. As projeções de luz, as cores diferentes e os espaços parecem engolir os personagens, a que restam somente fazer poses tanto quando o protagonista lê em casa, como quando se está só ou em grupo.

Não importa. Tudo são poses e imagens fugazes que breves não serão diante do inverno que se aproxima no poema de Baudelaire, diante do fim de mais uma festa, diante da passagem do tempo. A volta para casa adormecido, junto com a amiga, talvez seja a volta para um mundo entre a vigília e o sonho de onde nunca, de fato, saímos. Talvez a solidão fique. A solidão é cheia de pequenas mudanças de luz, de tempos a serem preenchidos, em que se tem de ser companheiro de si mesmo. Mas a solidão também é um corpo 
pleno no mundo, entre outras coisas, pessoas e espaços. Igualmente plenos e sós. É um corpo que é. Sem falta. A solidão é a gente demais, como Cao Guimarães cita João Guimarães Rosa no fim de seu filme Alma do Osso (2004).

A recuperação de Baudelaire se dá no mundo da cultura midiática, de imersão em luzes, cores, pessoas e na música eletrônica. Nada de busca de uma materialidade da terra, da natureza. A sensação se mescla ao artifício como gesto e pose, corpo e roupa. Seria o personagem criado por André Antônio a figura do dândi possível hoje em dia, como os personagens que ele estuda nos filmes de Sofia Coppola e de outros cineastas? Se o dândi, nos termos de Baudelaire (1988), ainda poderia ter uma postura heroica, e mesmo de diferenciação em relação ao mundo homogêneo e heternormativo burguês, como seria possível falar de dândismo na cultura massiva? Ele estaria no camp, como para Sontag? Ou se traduziria em ícones como Andy Warhol, em quem 0 apelo à superfície se traduz num espelho que reflete 0 mundo e todos; nas máscaras contínuas de Bowie, só encerradas com a morte; no corpo simulacral da modelo-cantora Grace Jones? Superfície que é máscara, pele vestida, imagem, não carne e matéria não alheia a sensações, mas distante da dissolução erótica, pois tudo já está desde sempre disperso, alheio, fragmentado. Na "sociedade de alta visibilidade" (PEREIRA; HERSCHMANN, 2005), marcada pela espetacularização da subjetividade, sejam as pessoas celebridades ou não, tenham ou não os seus 15 minutos de fama, como previa Warhol, elas se comportam como uma. Esta performance diária está ao alcance de todos, como se tivéssemos num reality show. Nesse sentido, a questão é qual a nossa performance, qual é a nossa imagem e não pensar a sociedade como espetáculo em que a imagem fosse apenas compreendida como mercadoria, como na conhecida formulação: "0 espetáculo é o capital em tal grau de acumulação que se torna imagem" (DEBORD, 1997, 25), porque a imagem que nos atravessa e nos institui, pelo século XX em diante, é cada vez mais sensação, afeto, memória e cotidiano, mesmo depois quando a festa acaba.

Sexo e gênero me interessam menos do que sensações e afetos. Claro, eles podem ser relacionados. Talvez seja só uma questão de ênfase ou onde estou agora. 0 que me faz continuar é o jogo de olhares. A beleza do mundo é 0 espetáculo das imagens. Poses. Não gestos. Máscaras. Não rostos. Peles. Não corpos. Tudo o que é artifício e superfície.

\section{Referências}

ANTELO, Raul. João do Rio: o Dândi e a Especulação Rio de Janeiro: Taurus, 1989.

APPADURAI, Arjun. Modernity at Large. Cultural Dimensions of Globalization. Minneapolis: University of Minnesotta Press, 1996.

BARB0SA, André Antônio. Projeto de qualificação à tese de doutorado 0s Labirintos da Frivolidade: Cinema e Artifício. Rio de Janeiro: UFRJ, 2014. BARTHES, Roland. Prazer do Texto. São Paulo: Perspectiva, 2008. 
BAUDELAIRE, Charles. "Dândi" In: COELHO, Teixeira (org.). A Modernidade de Baudelaire. Rio de Janeiro: Paz e Terra, 1988.

BENETTI, Fernando José. A Bicha Louca está fervendo: uma reflexão sobre a emergência da teoria queer no Brasil (1980-2013), Monografia de graduação, Florianópolis: Udesc, 2013.

BOLlON, Patrice. A Moral da Máscara. Rio de Janeiro: Rocco, 1993.

BUTLER, Judith. Gender Troubles: Feminism and the Subversion of Identity. Londres/New York: Routledege, 1990.

Bodies that Matter. On the

Discoursive Limits of Sex. New York/Londres: Routledge, 1993.

CANCLINI, Néstor García. Culturas híbridas. São Paulo: Edusp, 1997.

CHARNEY, Leo. Empty Moments: Cinema, Modernity and Drift. Durham: Duke University Press, 1998.

COLLING, Leandro. Quatro dicas preliminares para transar a genealogia do queer no Brasil. In BENTO, Berenice (org.). Desfazendo Gênero: Subjetividade, Cidadania, Transformismo. Natal: EDUFRN, 2015.

COSTA, Jurandir Freire. A Inocência e o Vício:

Estudos sobre o Homoerotismo. Rio de Janeiro: Relume-Dumará, 1992.

DELEUZE, G; GUATTARI, F. "Percepto, Afeto e Conceito" In: 0 que é a filosofia? Rio de Janeiro: 34, 1992.

DEBORD, Guy. A Sociedade do Espetáculo. Rio de Janeiro: Contraponto, 1997.

DEL RIO, Elena. Powers of Affection: Deleuze and the Cinemas of Performance. Edinburgh: Edinburgh University Press, 1998.

DOYLE, Jennifer. Hold it against me: Emotion and Difficulty in Contemporary Art. Durham: Duke University Press, 2013.
DUQUE, Gonzaga. Mocidade Morta. Rio de Janeiro: Fundação Casa de Rui Barbosa, 1995.

Horto de mágoas: contos. Rio de

Janeiro: Biblioteca Carioca, 1996. . Graves e frívolos, por assuntos de arte. Rio de Janeiro: Casa de Rui Barbosa. 7Letras, 1997. ECHAVARREN, Roberto. Arte Androgino. Buenos Aires: Colihue, 1998.

ECHEVERRIA, Bolívar. "Queer, manierista, bizarre, barroco". Debate Feminista, vol. 8, n.16, v. 19, 1997, p. $3-10$.

GALLO, Rubén. Proust's Latin Americans. Baltimore: Johns Hopkins University Press, 2014.

GARCIA, Wilton. Homoerotismo e Imagem no Brasil. São Paulo: Nojosa/Fapesp, 2004.

GARELICK, Rhonda. Rising Star: Gender, Dandyism, Gender and the Performance in the Fin de Siècle. Princeton: Princeton University Press, 1998.

GATTI, José; PENTEAD0, Fernando Marques (orgs). Masculinidades: teoria, crítica e artes. São Paulo: Estação das Letras e Cores, 2011

GREEN, James. Além do Carnaval: a

Homossexualidade masculina no Brasil do século XX. São Paulo: Ed. da Unesp, 2000.

GUATTARI, Félix e ROLNIK, Suely. Micropolítica: Cartografias do Desejo. Petrópolis: Vozes, 1996. (Original 1986)

HALBERSTAM, Judith. The Queer Art of Failure. Durham: Duke University: 2011.

HUYSMANS, Joris Karls. Às Avessas. São Paulo: Companhia das Letras, 1987.

LARKOSH, Cristopher. Aqueles Dois: As cartografias multilíngues de Néstor Perlongher e Caio Fernando Abreu. Estudios: Revista de Investigaciones Literarias y Culturales, 24, 2004. 
LEVIN, Orna Messer. As figurações do Dândi: um estudo sobre a obra de João do Rio. Campinas: EdUNICAMP, 1996.

LINS, Vera. Gonzaga Duque: a estratégia do franco atirador. Rio de Janeiro: Tempo Brasileiro, 1991. Gonzaga Duque: crítica e utopia na virada do século. Rio de Janeiro: Fundação Casa Ruy Barbosa, 1996.

LOPES, Denilson. Nós os Mortos: Melancolia e NeoBarroco. Rio de Janeiro: 7Letras, 1999.

0 Homem que Amava Rapazes e

Outros Ensaios. Rio de Janeiro: Aeroplano, 2002. Afectos Pictóricos ou em Direção a

Transeunte de Eryk Rocha. Revista Famecos, v.20, $\mathrm{n}^{0} 2,2013$.

LOURO, Guacira Lopes. 0 Corpo Estranho: Ensaio sobre Sexualidade e Teoria Queer. Belo Horizonte: Autêntica, 2004.

LUGARINHO, Mario. Como traduzir a teoria queer para a língua portuguesa. Gênero. vol. 1, nº 2, 2001.

MAIA, Helder Thiago. Devir Darkroom e a Literatura Hispano-Americana. Rio de Janeiro: Multifoco, 2014.

MISKOLCI, Richard e PELÚCIO, Larissa. Aquele não mais obscuro objeto do desejo In: Perlongher, Néstor, 0 Negócio do Michê: a Prostituição Viril em São Paulo. $2^{\mathrm{a}}$. ed. São Paulo: Editora Fundação Perseu Abramo, 2008.

MISKOLCI, Richard. Teoria Queer: um Aprendizado pelas Diferenças. Belo Horizonte/Ouro Preto, Autêntica/UFOP, 2012.

MOLLOY, Sylvia. La Cuestión del género: propuestas olvidadas y desafíos críticos. Iberoamericana. vol. 66, n. $193,2000,815-819$.

Poses de Fin de Siglo: Desbordes

del Género en la Modernidad. Buenos Aires: Eterna Cadencia, 2012.
MONSIVAIS, Carlos. Salvador Novo: Lo Marginal en

lo Centro. Mexico: Era, 2000.

MUCCI, Latuf. Ruína e Simulacro Decadentista. Rio de Janeiro: Tempo Brasileiro, 1994.

MUÑOZ, José. Cruising Utopia. The Then and There of Queer Futurity. New York: New York University, 2009.

PALMEIR0, Cecilia. Desbunde y Felicidad: de la

Cartonera a Perlongher. Buenos Aires: Titulo, 2011.

PEIXOTO, Mário. 0 Inútil de Cada Um. Rio de Janeiro: Record, 1984.

PEREIRA, Carlos Alberto Messeder ; HERSCHMANN, Micael. 0 espetáculo contemporâneo. In: Herschmann, Micael; Pereira, Carlos Alberto Messeder (Orgs.).

Mídia, Memória e Celebridades. Estratégias narrativas em contextos de alta visibilidade. $2^{\mathrm{a}} \mathrm{ed}$., Rio de Janeiro: Ed. E-Papers, 2005.

PERLONGHER, Néstor. Prosa plebeya. Buenos Aires: Colihue, 1997.

Negócio do Michê: a Prostituição Viril em São Paulo. São Paulo: Brasiliense, 1987.

PRATT, Mary Louise. Pós-Colonialidade: Projeto Incompleto ou Irrelevante? In: VÉSCIO, Luiz Eugênio e SANTOS, Pedro Brum (orgs.). Literatura \& História. Bauru: Edusc, 1999.

QUIR0GA, José. Tropics of Desire. New York: New York University Press, 2000.

RICAIDE, Maricruz Castro. Género In. IRWIN. Robert e SZURMUK, Mónica (orgs. ). Diccionario de Estudios Culturales Latinoamericanos, México: Siglo Vinte e Uno/Instituto Mora, 2009.

SANTIAG0, Silviano. 0 Entre-lugar do Discurso LatinoAmericano In: Uma Literatura nos Trópicos. São Paulo: Perspectiva, 1978. Vale Quanto Pesa. Rio de Janeiro. Paz e

Terra, 1982. 
. 0 Homossexual Astucioso In: 0

Cosmopolitismo do Pobre. Belo Horizonte: UFMG, 2004.

SARDUY, Severo. Ensayos Generales sobre el Barroco.

Buenos Aires: Fondo del Cultura Económica, 1987.

SEDGWICK, Eve Kosofsky; FRANK, Adam. Shame in

Cybenetic Fold: Reading Silvan Tomkins In: SEDGWICK, Eve Kosofsky. Touching Feeling: Affect, Pedagogy,

Performativitty. Durham: Duke University Press, 2003.

SONTAG, Susan. Notas sobre Camp In: Contra a

Interpretação. Porto Alegre: L\&PM, 1987.

STOKER, Lawrence La Fontain. Queericans: Cultures and Sexualities in the Diaspora. Minneapolis:

University of Minnesotta Press, 2009.

SUTHERLAND, Juan Pablo. La Nación Marica.

Santiago: Ripio, 2009.

SUTHERLAND, Juan Pablo (org.). Cielo Dandi, Buenos Aires: Eterna Cadencia, 2011.

SWAIN, Tânia Navarro. Qui est queer?, [S. L.] 1997.

Disponível em http://www.tanianavarroswain.com.br/ francais/queer2.htm (19 de dezembro de 2014).

TREVISAN, João Silvério. Devassos no Paraíso. Rio de Janeiro, Record, 2000. (Original 1986) 


\begin{tabular}{|c|c|}
\hline $\begin{array}{l}\text { Affects, Queer Studies } \\
\text { and Artifice in Latin America }\end{array}$ & $\begin{array}{l}\text { Afectos, Estudios Queer y } \\
\text { Artificio en América Latina }\end{array}$ \\
\hline $\begin{array}{l}\text { Abstract } \\
\text { First we try to stablish a dialogue about affects } \\
\text { between Deleuze’s and Guattari’s ideas and queer } \\
\text { studies; Deleuze and Guattari clearly states the } \\
\text { connection between affect and art. On the other } \\
\text { side some recent works close to queer studies at the } \\
\text { Anglophone world use the expression affect without } \\
\text { a further development. Then we propose that this } \\
\text { dialogue should find a stimulating response by a } \\
\text { genealogy of Latin American intellectual production } \\
\text { based on artifice, giving special emphasis on camp. } \\
\text { As a way of trying to approach both perspectives at } \\
\text { a an analysis of Song of Autumn (2014) by André } \\
\text { Antônio Barbosa through a second way of translating } \\
\text { artifice: dandyism. } \\
\text { Keywords } \\
\text { Affect: artifice: camp: dandvism: queer studies }\end{array}$ & $\begin{array}{l}\text { Resumen } \\
\text { En la primera parte, intentaré sugerir un diálogo } \\
\text { entre afectos y estudios queer. Si Deleuze y Guattari } \\
\text { hacen fuertes entre relaciones entre arte y afecto, } \\
\text { trabajos de autores asociados a los estudios queer } \\
\text { em el mundo anglohablane no se sirven, por lo menos } \\
\text { explícitamente, de un cuestionamiento sobre afectos. } \\
\text { Este diálogo encuentra uma respuesta estimulante } \\
\text { em uma genealogia de la producción latino- } \\
\text { americana relaciona al artificio, en especial en lo } \\
\text { que se refiere al camp. Como uma manera de acercar } \\
\text { ambas perspectivas analisaremos "Canto de outono" } \\
\text { de André Antônio Barbosa través uma segunda } \\
\text { manera de traducir el atificio: el dandismo } \\
\text { Palabras clave } \\
\text { Afecto; artificio; camp; dandismo; estudios queer }\end{array}$ \\
\hline
\end{tabular}




\section{Expediente}

A revista E-Compós é a publicação científica em formato eletrônico da Associação Nacional dos Programas de Pós-Graduação em Comunicação (Compós). Lançada em 2004, tem como principal finalidade difundir a produção acadêmica de pesquisadores da área de Comunicação, inseridos em instituições do Brasil e do exterior.

\section{E-COMPÓS I www.e-compos.org.br I E-ISSN 1808-2599}

Revista da Associação Nacional dos Programas de Pós-Graduação em Comunicação. Brasília, v.19, n.2, maio/ago. 2016. A identificação das edições, a partir de 2008, passa a ser volume anual com três números. Indexada por Latindex I www.latindex.unam.mx

\section{CONSELHO EDITORIAL}

\section{Alexandre Farbiarz, Universidade Federal Fluminense, Brasi}

Alexandre Rocha da Silva, Universidade Federal do Rio Grande do Sul, Brasil Ana Carolina Escosteguy, Pontifícia Universidade Católica do Rio Grande do Sul, Brasil Ana Carolina Rocha Pessôa Temer, Universidade Federal de Goiás, Brasil Ana Regina Barros Rego Leal, Universidade Federal do Piauí, Brasil Andrea França, Pontifícia Universidade Católica do Rio de Janeiro, Brasil André Luiz Martins Lemos, Universidade Federal da Bahia, Brasil Antonio Carlos Hohlfeldt, Pontifícia Universidade Católica do Rio Grande do Sul, Brasil Arthur Ituassu, Pontifícia Universidade Católica do Rio de Janeiro, Brasil Álvaro Larangeira, Universidade Tuiuti do Paraná, Brasil

Ângela Freire Prysthon, Universidade Federal de Pernambuco, Brasil César Geraldo Guimarães, Universidade Federal de Minas Gerais, Brasil Cláudio Novaes Pinto Coelho, Faculdade Cásper Líbero, Brasil Daisi Irmgard Vogel, Universidade Federal de Santa Catarina, Brasil Denize Correa Araujo, Universidade Tuiuti do Paraná, Brasil Eduardo Antonio de Jesus, Pontifícia Universidade Católica de Minas Gerais, Brasil Daniela Zanetti, Universidade Federal do Espírito Santo, Brasil Eduardo Vicente, Universidade de São Paulo, Brasil

Elizabeth Moraes Gonçalves, Universidade Metodista de São Paulo, Brasil Erick Felinto de Oliveira, Universidade do Estado do Rio de Janeiro, Brasil Francisco Elinaldo Teixeira, Universidade Estadual de Campinas, Brasil Francisco Paulo Jamil Almeida Marques, Universidade Federal do Paraná, Brasil Gabriela Reinaldo, Universidade Federal do Ceará, Brasil

Goiamérico Felício Carneiro Santos, Universidade Federal de Goiás, Brasil Gustavo Daudt Fischer, Universidade do Vale do Rio dos Sinos, Brasil Herom Vargas, Universidade Municipal de São Caetano do Sul, Brasil Itania Maria Mota Gomes, Universidade Federal da Bahia, Brasil Janice Caiafa, Universidade Federal do Rio de Janeiro, Brasil Jiani Adriana Bonin, Universidade do Vale do Rio dos Sinos, Brasil
José Afonso da Silva Junior, Universidade Federal de Pernambuco, Brasil José Luiz Aidar Prado, Pontifícia Universidade Católica de São Paulo, Brasil Juçara Gorski Brittes, Universidade Federal de Ouro Preto, Brasil Kati Caetano, Universidade Tuiuti do Paraná, Brasil Lilian Cristina Monteiro França, Universidade Federal de Sergipe, Brasil Liziane Soares Guazina, Universidade de Brasilia, Brasil Luíza Mônica Assis da Silva, Universidade de Caxias do Sul, Brasil Luciana Miranda Costa, Universidade Federal do Pará, Brasil Malena Segura Contrera, Universidade Paulista, Brasil Monica Martinez, Universidade de Sorocaba, Brasil Maria Ataide Malcher, Universidade Federal do Pará, Brasil Marcia Tondato, Escola Superior de Propaganda e Marketing, Brasil Marcel Vieira Barreto Silva, Universidade Federal da Paraiba, Brasil Maria Clotilde Perez Rodrigues, Universidade de São Paulo, Brasil Maria das Graças Pinto Coelho, Universidade Federal do Rio Grande do Norte, Brasil Mauricio Ribeiro da Silva, Universidade Paulista, Brasil

Mauro de Souza Ventura, Universidade Estadual Paulista, Brasil Márcio Souza Gonçalves, Universidade do Estado do Rio de Janeiro, Brasil Micael Maiolino Herschmann, Universidade Federal do Rio de Janeiro, Brasil Mirna Feitoza Pereira, Universidade Federal do Amazonas, Brasil Nísia Martins Rosario, Universidade Federal do Rio Grande do Sul, Brasil Potiguara Mendes Silveira Jr, Universidade Federal de Juiz de Fora, Brasil Regiane Regina Ribeiro, Universidade Federal do Paraná, Brasil Rogério Ferraraz, Universidade Anhembi Morumbi, Brasil Rose Melo Rocha, Escola Superior de Propaganda e Marketing, Brasil Rozinaldo Antonio Miani, Universidade Estadual de Londrina, Brasil Sérgio Luiz Gadini, Universidade Estadual de Ponta Grossa, Brasil Simone Maria Andrade Pereira de Sá, Universidade Federal Fluminense, Brasil Veneza Mayora Ronsini, Universidade Federal de Santa Maria, Brasil Walmir Albuquerque Barbosa, Universidade Federal do Amazonas, Brasil
COMISSÃO EDITORIAL Eduardo Antonio de Jesus, Pontifícia Universidade Católica de Minas Gerais, Brasil I Osmar Gonçalves dos Reis Filho, Universidade Federal do Ceará, Brasi

CONSULTORES AD HOC Alexandre Almeida Barbalho, Universidade Estadual do Ceará, Brasil | Alexandre Rocha da Silva, Universidade Federal do Rio Grande do Sul, Brasil | Bruno Souza Leal, Universidade Federal de Minas Gerais, Brasil I Carlos Eduardo Franciscato, Universidade Federal do Sergipe, Brasil I Eneus T. Barreto Filho, Universidade de São Paulo, Brasil I Felipe da Costa Trotta, Universidade Federal Fluminense, Brasi | Henrique Codato, Universidade Federal do Ceará, Brasil I Ines S. Vitorino Sampaio Universidade Federal do Ceará, Brasil I Jairo Getulio Ferreira, Universidade do Vale do Rio dos Sinos, Brasil I Juliana Freire Gutmann, Universidade Federal da Bahia, Brasil | Júlio César M. Pinto, Pontifícia Universidade Católica de Minas Gerais, Brasil I Lucrecia D. Ferrara, Pontifícia Universidade Católica de São Paulo, Brasil I Marcio V. Serelle, Pontifícia Universidade Católica de Minas Gerais, Brasil I Maria Ignes C. Magno, Universidade Anhemb Morumbi, Brasil I Maria Lilia Dias de Castro, Universidade Federal de Santa Maria, Brasil | Mozahir S. Bruck, Pontifícia Universidade Católica de Minas Gerais, Brasil I Potiguara M. da Silveira Junior, Universidade Federal de Juiz de Fora, Brasil I Sandra Maria L. P. Gonçalves, Universidade Federal do Rio Grande do Sul, Brasil I Suzana Kilpp, Universidade do Vale do Rio dos Sinos, Brasil I Tiago Q. Fausto Neto, Universidade de Brasília, Brasil I Vera Regina V. Franca, Universidade Federal de Minas Gerais, Brasil I Virginia P. S. Fonseca, Universidade Federal do Rio Grande do Sul, Brasil

EQUIPE TÉCNICA ASSISTENTE EDITORIAL Márcio Zanetti Negrini REVISÃo DE TEXTOS Press Revisão I EDITORAÇÃO ELETRÔNICA Roka Estúdio

\section{COMPÓS I www.compos.org.br}

Associação Nacional dos Programas de Pós-Graduação em Comunicação

Presidente

Edson Fernando Dalmonte

Programa de Pós-Graduação em Comunicação

e Cultura Contemporânea - UFBA

edsondalmonte@uol.com.br

Vice-presidente

Cristiane Freitas Gutfreind

Programa de Pós-Graduação em Comunicação Social - PUC-RS cristianefreitas@pucrs.br

Secretário-Geral

Rogério Ferraraz

Programa de Pós-Graduação em Comunicação

Universidade Anhembi Morumbi

rogerioferraraz@anhembimorumbi.edu.br

CONTATO I revistaecompos@gmail.com 